\title{
Rotations in a shear-beam model of a seven-story building caused by nonlinear waves during earthquake excitation
}

\author{
V. Gičev ${ }^{1}$ and M. D. Trifunac ${ }^{2, *, \dagger}$ \\ ${ }^{1}$ Rudarsko-geoloski fakultet, Goce Delcev 89, 2000 Stip, Republic of Macedonia \\ ${ }^{2}$ Department of Civil Engineering, University of Southern California, Los Angeles, CA 90089, U.S.A.
}

\begin{abstract}
SUMMARY
We model a seven-story, reinforced-concrete building in Van Nuys, CA, which was damaged during the 1994 Northridge earthquake. We use a one-dimensional, layered, shear-beam model with bi-linear material properties, and we examine how the rotations (local strains and drifts) in this model depend upon the distribution of the stiffness along the building height, the nonlinear properties of the reinforced concrete, and the nature of strong motion. We show how, following the powerful waves propagating up and down the building, point rotations take place that differ from the corresponding average drift angles. These point rotations are larger near the rigid floor slabs (near the top and bottom ends of the columns, shear walls, and nonstructural members found at all floors) and propagate as slow waves up and down the building. These slow rotational waves occur only while the material is experiencing large nonlinear deformations, and their amplitudes grow with ductility. We note that recording these rotational waves in real time may provide a powerful new vehicle for health monitoring of full-scale structures excited by large transient forces when their structural members enter large nonlinear deformations. Copyright (C) 2008 John Wiley \& Sons, Ltd.
\end{abstract}

KEY WORDS: structural health monitoring; real-time recording of rotations induced by nonlinear waves; detection of damage by earthquakes; impacts and explosions

\section{INTRODUCTION}

The real-time detection of damage in buildings has become one of the contemporary challenges in structural dynamics for powerful transient excitations by earthquakes, impact loads, and explosions. The goal is to detect the location, the extent, the nature, and the time of occurrence of the damage. Having detected the damage, the objective is then to provide a real-time means of dealing with its consequences. In this paper, we explore how the point rotations at selected points in the structure could be used for this purpose, and we explore the physical nature of this

*Correspondence to: M. D. Trifunac, Department of Civil Engineering, University of Southern California, Los Angeles, CA 90089, U.S.A.

†E-mail: trifunac@usc.edu 
problem using a simple one-dimensional (1D) representation of a real structure. We note that recording strong-motion rotations can become a powerful tool for real-time damage detection.

Most health-monitoring methods for civil engineering structures use structural vibration data and are based on detecting changes in their modal parameters-frequencies and mode shapes (e.g. see Doebling et al. [1] and Chang et al. [2] for detailed state-of-the-art reviews on this topic). While monitoring changes in the frequencies of vibration requires minimum instrumentation, monitoring changes in the mode shapes requires more extensive instrumentation than is available in even most instrumented structures. Furthermore, the frequencies of vibration are usually estimated using some energy distribution of the recorded response in the time-phase plane. The difficulty associated with this approach is that the changes caused by damage can be small relative to the time-dependent fluctuations of full-scale structures, noise, and the uncertainties associated with damage location.

There are two main advantages of formulating the structural health monitoring in terms of the wave-propagation method, which will be used in this paper. One advantage is that it is local (the wave travel times depend only upon the properties of the structure between the adjacent observation points). In contrast, the modal methods are global (the modal properties depend upon the overall properties of the structure, and therefore they change little when the damage is localized). The wave methods can detect local changes with relatively few sensors (as compared with detecting changes in mode shapes). Another advantage is that the wave travel time through the building can provide information that is directly related to the properties of the structure alone. In contrast, the time frequency energy distributions yield the frequency of the soil-structure system, $f_{\text {sys }}$, which also depends upon the stiffness of soil and therefore describes the changes in the soil-structure system, not in the structure alone. The changes in $f_{\text {sys }}$ have often been erroneously interpreted to be entirely due to loss of structural stiffness (e.g. [3-6]). For comprehensive and reliable structural health monitoring, it is therefore essential to be able to monitor the changes in the structure alone, and wave-propagation methods are among the most suitable for this purpose.

There are only a few publications on wave-propagation methods for analyses of building response, other than nondestructive testing, for structural health monitoring and damage detection in civil structures [7-13]. Safak [14] proposed a layered continuous model for analysis of seismic response of a building and detection of damage by tracing changes in the parameters in the layers. Ivanović et al. [15] and Trifunac et al. [16] used strong-motion data recorded in an eight-story, reinforced-concrete building during the 1994 Northridge earthquake to explore two methods, one based on cross-correlation analysis (to estimate time lags between motions recorded at different levels) and the other based on detecting changes in wave numbers (inversely proportional to the wave velocities) of waves propagating between different levels. Ma and Pines [17] proposed a method based on a lumped mass building model and propagation of de-reverberated waves to identify the damage, which can be tested using simulated building response data. Gičev and Trifunac $[18,19]$ used the energy and power of nonlinear waves to identify the location of damage. The first applications of the impulse-response functions computed by deconvolution [20] for detecting local changes in stiffness, and for earthquake damage detection in general, appeared in the studies of the seven-story Van Nuys Hotel $[21,22]$ and the Imperial County Services Building [23-25].

Rotational components of building motion accompany the displacements induced by seismic waves. In linear elastic media, 'point rotations' are expressed by space derivatives of the 
displacements [26]. 'Average rotations' (rotation of a line connecting two moving points and separated by a known distance) can be computed from the differences in the recordings of two translational records of the response [27-29].

During nonlinear wave propagation in buildings, point rotations can become large, especially in the areas of strain localization. In the following, we present a simple model that allows us to study these large point rotations in a shear-beam model of a seven-story building. We show how these rotations relate to the overall amplitudes and time characteristics of the response. Consideration of other contributions to point and average rotations, such as departures of real building behavior from the simple shear-beam model, and geometric nonlinear deformations of a structure, for example, are outside the scope of this paper.

\section{CASE STUDY-VAN NUYS HOTEL (VN7SH)}

The building whose response we analyze in this paper using a 1D, layered, nonlinear shear-beam model is a seven-story hotel (VN7SH) located in Van Nuys, CA. It was damaged by the 1994 Northridge, California earthquake [30-33]. Designed in 1965 and constructed in 1966 $[34,35]$, it is $18.9 \times 45.7 \mathrm{~m}$ in plan and is $20 \mathrm{~m}$ high. The typical framing consists of four rows of columns spaced on $6.1 \mathrm{~m}$ centers in the transverse direction and $5.7 \mathrm{~m}$ centers in the longitudinal direction (nine columns) (Figure 1(a)). Spandrel beams surround the perimeter of the structure. Lateral forces in the longitudinal (EW) direction are resisted by interior column-slab frames (B and C) and exterior column-spandrel beam frames (A and D). The added stiffness in the exterior frames associated with the spandrel beams creates exterior frames that are roughly twice as stiff as interior frames. The floor system is reinforced-concrete flat slab, $25.4 \mathrm{~cm}$ thick at the second floor, $21.6 \mathrm{~cm}$ thick at the third to seventh floors, and $20.3 \mathrm{~cm}$ thick at the roof [3-6,34]. The building is situated on undifferentiated Holocene alluvium, uncemented and unconsolidated, with a thickness of $<30 \mathrm{~m}$, and an age of $<10000$ years [36]. The average shear-wave velocity in the top $30 \mathrm{~m}$ of soil is $300 \mathrm{~m} / \mathrm{s}$, and the soil-boring $\log$ shows that the underlying soil consists primarily of fine sandy silts and silty fine sands. The foundation system consists of $96.5-\mathrm{cm}$-deep pile caps supported by groups of two to four poured-in-place, 61-cm-diameter, reinforced-concrete friction piles. These are centered under the main building columns, and all of the pile caps are connected by a grid of beams. Each pile is approximately $12.2 \mathrm{~m}$ long and has a design capacity of over $444.82 \times 10^{3} \mathrm{~N}$ vertical load and up to $88.96 \times 10^{3} \mathrm{~N}$ lateral load. The structure is constructed of normal-weight reinforced concrete [34].

\subsection{Earthquake damage}

The $M_{\mathrm{L}}=6.4$ Northridge earthquake of January 17,1994 , severely damaged the building. The structural damage was extensive in the exterior north (D) (Figure 2, top) and south (A) (Figure 2 , bottom) frames that were designed to take most of the lateral load in the longitudinal (EW) direction. Severe shear cracks occurred at the middle columns of frame A, near the contact with the spandrel beam of the fifth floor (Figures 2 and 3), and those cracks significantly decreased the axial, moment, and shear capacity of the columns. The shear cracks that appeared in the north (D) frame (Figure 2, top) caused minor to moderate changes in the capacities of these structural elements. No major damage to the interior longitudinal (B and C) frames was 


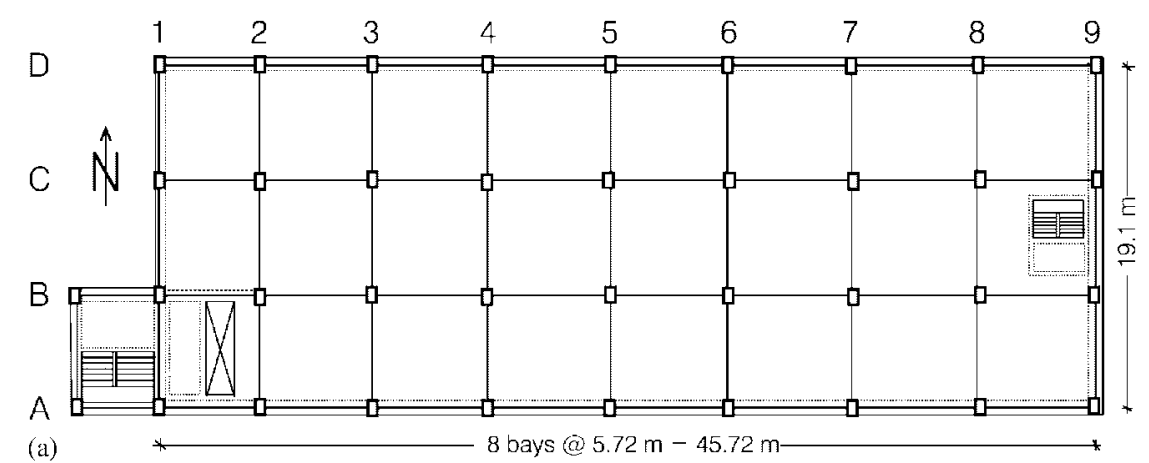

(a)

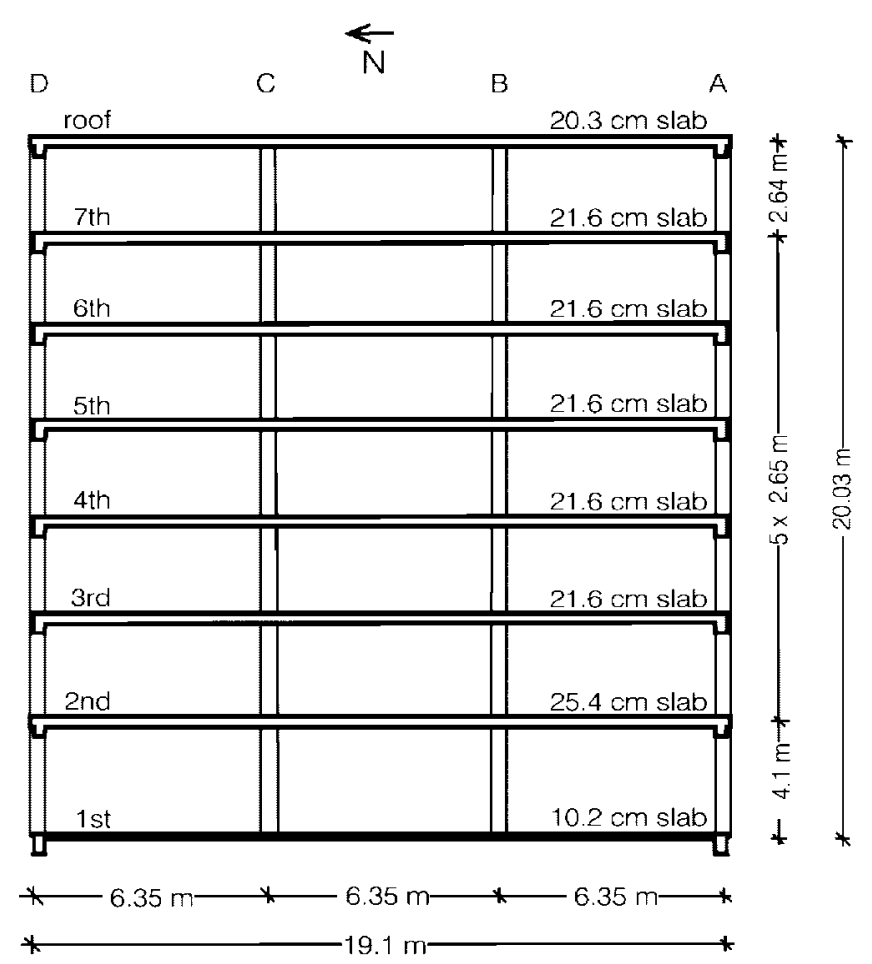

Figure 1. Van Nuys seven-story hotel (VN7SH): (a) typical floor plan and (b) typical transverse section.

observed, and there was no visible damage to the slabs or around the foundation. The nonstructural damage was significant. Photographs and detailed descriptions of the damage from the earthquake can be found in Trifunac et al. [33] and Trifunac and Hao [31]. An analysis of the relationship between the observed damage and the changes in equivalent vertical shearwave velocity in the building can be found in [21]. A discussion of the extent to which this damage has contributed to the changes in the apparent period of the soil-structure system can be found in $[37,38]$. 

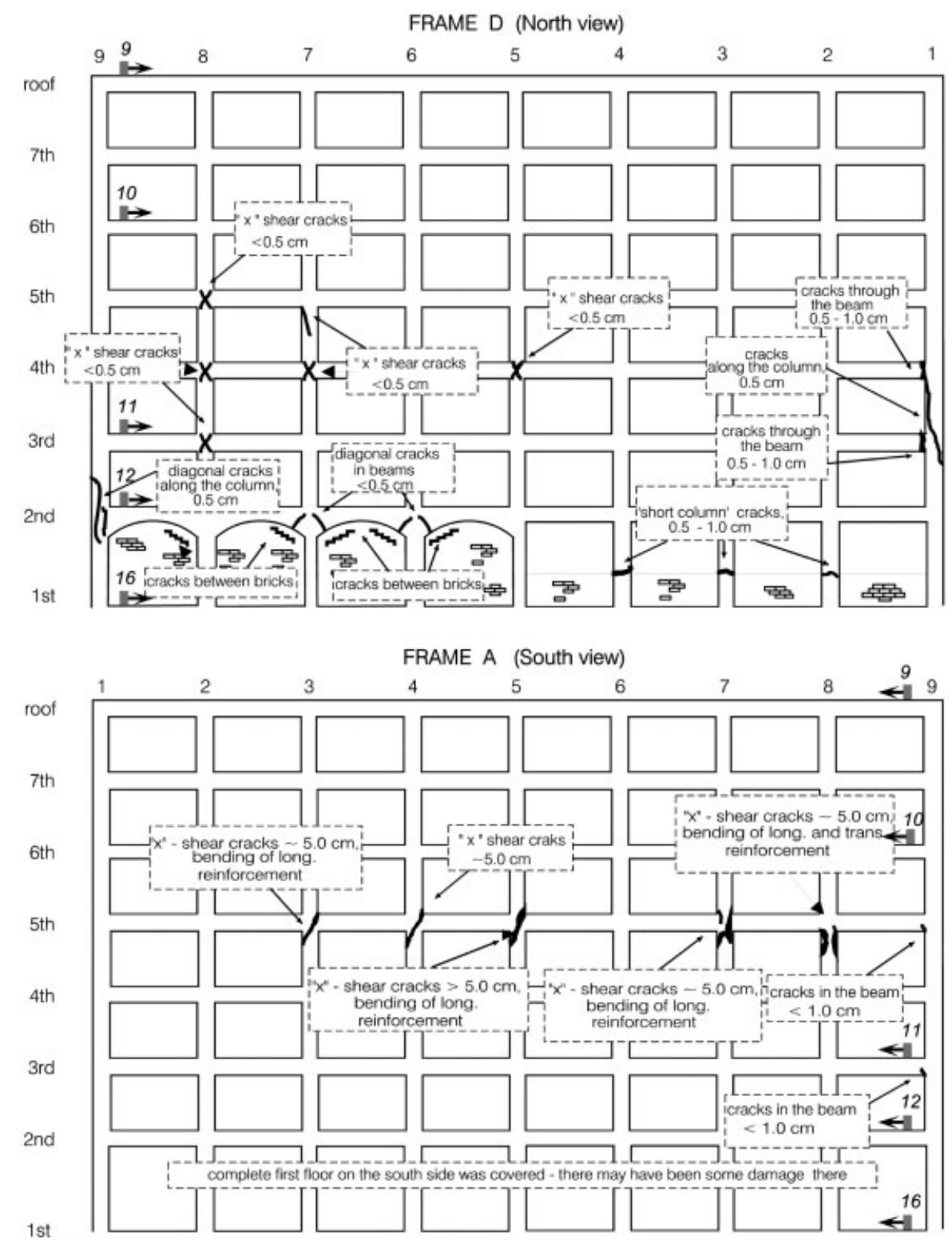

Figure 2. Observed damage to frames A and D.

\section{NONLINEAR WAVES}

In the 1D model adopted for this study, we use the velocity of shear waves and the density of the slabs and inter-story columns based on the analysis of impulse response for EW recorded motions in the Holiday Inn Hotel [21]. These parameters, together with the story heights, are summarized in Table I. As can be seen from Table I, the stiffness and the density of the floors 


\section{GIČEV AND M. D. TRIFUNAC}

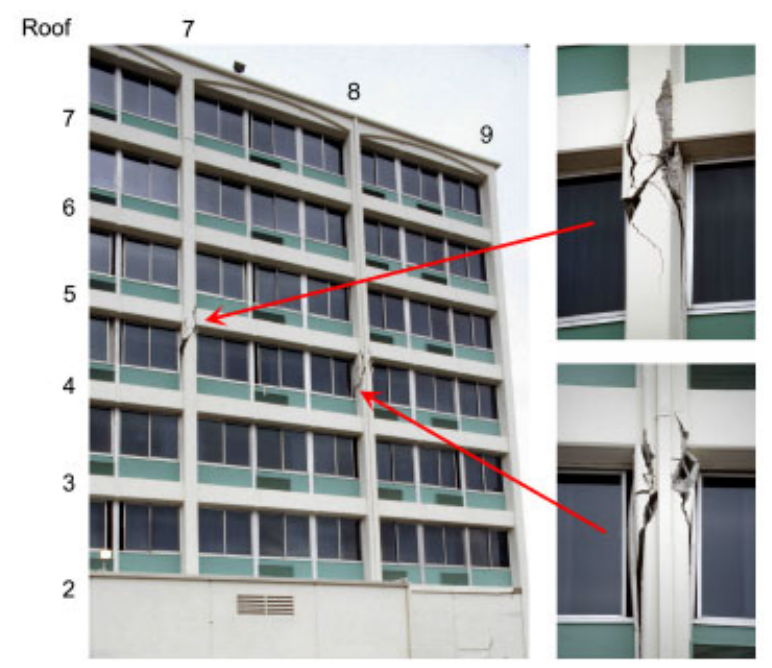

Figure 3. Post-earthquake view of damaged columns A7 and A8 in frame A (see Figures 1 and 2).

Table I. One-dimensional building model.

\begin{tabular}{|c|c|c|c|c|c|c|}
\hline & $\begin{array}{l}\text { Interstory height } \\
h_{\text {inter-stosry }}(\mathrm{m})\end{array}$ & $\begin{array}{c}\text { Slab thickness } \\
h_{\text {slab }}(\mathrm{m})\end{array}$ & $\begin{array}{c}\beta_{\text {inter-story }} \\
(\mathrm{m} / \mathrm{s})\end{array}$ & $\beta_{\text {slab }}(\mathrm{m} / \mathrm{s})$ & $\begin{array}{c}\beta_{\text {inter-story }} \\
\left(\mathrm{kg} / \mathrm{m}^{3}\right)\end{array}$ & $\underset{\left(\mathrm{kg} / \mathrm{m}^{3}\right)}{\beta_{\text {slab }}}$ \\
\hline Roof slab & & 0.203 & & 2000 & & 2384 \\
\hline Seventh story & 2.44 & & 73.15 & & 82.90 & \\
\hline Seventh-floor slab & & 0.215 & & 2000 & & 2384 \\
\hline Sixth story & 2.44 & & 76.20 & & 82.90 & \\
\hline Sixth-floor slab & & 0.216 & & 2000 & & 2384 \\
\hline Fifth story & 2.44 & & 77.72 & & 82.90 & \\
\hline Fifth floor-slab & & 0.216 & & 2000 & & 2384 \\
\hline Fourth story & 2.44 & & 79.25 & & 82.90 & \\
\hline Fourth-floor slab & & 0.216 & & 2000 & & 2384 \\
\hline Third story & 2.44 & & 91.44 & & 82.90 & \\
\hline Third-floor slab & & 0.216 & & 2000 & & 2384 \\
\hline Second story & 2.44 & & 129.50 & & 82.90 & \\
\hline Second-floor slab & & 0.254 & & 2000 & & 2384 \\
\hline First story & 3.86 & & 140.20 & & 76.92 & \\
\hline
\end{tabular}

are much larger than the stiffness of the columns, so it can be expected that the floors will remain linear and move as rigid bodies.

To select the final model parameters - the yielding and strengthening of the material - we calculated the east-west response of the model without considering the soil-structure interaction, with the assumption that the input ground motion (Figure 4) can be approximated by the strong motion recorded at the structure's ground floor (channel 16 in Figure 2, [39]). We then compared the results with the recorded motions at higher floors in the building (channel 12 at the second floor, channel 11 at the third floor, channel 10 at the sixth 


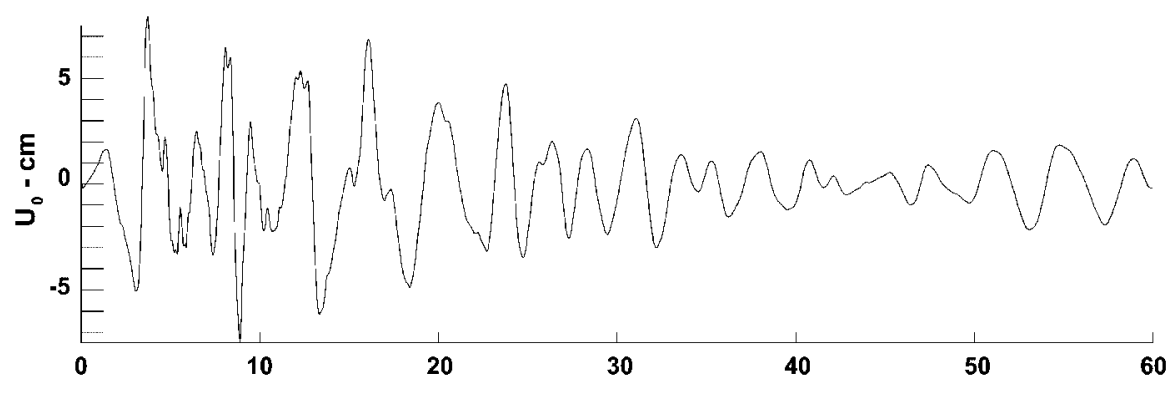

Figure 4. Incident ground motion.

floor, and channel 9 at the roof). The locations of the instruments in the building that recorded the EW response are shown in Figure 2.

By trial and error search for the best value of the yielding strain and the bi-linear approximation of the material properties, we obtained the best estimates for yielding strain $\epsilon_{\mathrm{y}}=0.0025$ and for strengthening parameter $\gamma=0.44$. These two parameters, together with the material velocities, densities, and dimensions, shown in Table I, then describe the required physical properties of the model whose response we analyzed by finite differences (FD) $[39,40]$.

Our 1D model consists of 14 layers representing seven floor slabs and seven inter-story columns, with dimensions (thickness) of the layers $h(i)$, velocities of shear waves $\beta(i)$, and densities $\rho(i)$, for $1 \leqslant i \leqslant 14$, where, $i=2 k-1(k=1,2, \ldots, 7)$ represent inter-story space (soft layers), and $i=2 k(k=1,2, \ldots, 7)$ represent floor slabs (hard layers) (see Table I, Figure 5).

We assume the bilinear constitutive law $\sigma=\sigma(\epsilon)$, where $\sigma$ is shear stress and $\varepsilon$ is shear strain at a grid point (Figure 6). The first slope, $\mu_{0 b}$, represents the linear (initial) shear modulus, and the second slope, $\mu_{1 b}=\gamma \mu_{0 b}$, represents the shear modulus after yielding. The yielding strain $\epsilon_{\mathrm{yb}}=0.0025$ and the strengthening $\gamma=0.44$ are assumed to be the same for all soft layers (solid lines in Figure 6). The contact points between two layers and the contact point between the soil and layer 1 remain in a linear state (dashed line in Figure 6) [39].

The equation of shear waves we used is

$$
v_{t}=\frac{1}{\rho}(\sigma)_{x}
$$

and the relationship between the derivatives of the strain and the velocity is

$$
\epsilon_{t}=v_{x}
$$

where $v, \rho, \sigma$, and $\varepsilon$ are particle velocity, density, shear stress, and shear strain, respectively, and the subscripts $t$ and $x$ represent derivatives with respect to time and space. $v=\partial u / \partial t$ and $\epsilon=\partial u / \partial x$ are the velocity and the strain of a particle, and $u$ is the out-of-plane displacement of a particle perpendicular to the velocity along the propagation ray.

The Lax-Wendroff $O\left(\Delta t^{2}, \Delta x^{2}\right)$ finite-difference method [41] for a set of simultaneous equations was used to solve the problem. The time increment is obtained from the minimum ratio:

$$
\Delta t=\left(\frac{\Delta x_{k}}{\beta_{k}}\right)_{\min }=\frac{\Delta x_{14}}{\beta_{14}}
$$

where the subscripts stand for the layer number counted from the base. 


\section{GIČEV AND M. D. TRIFUNAC}

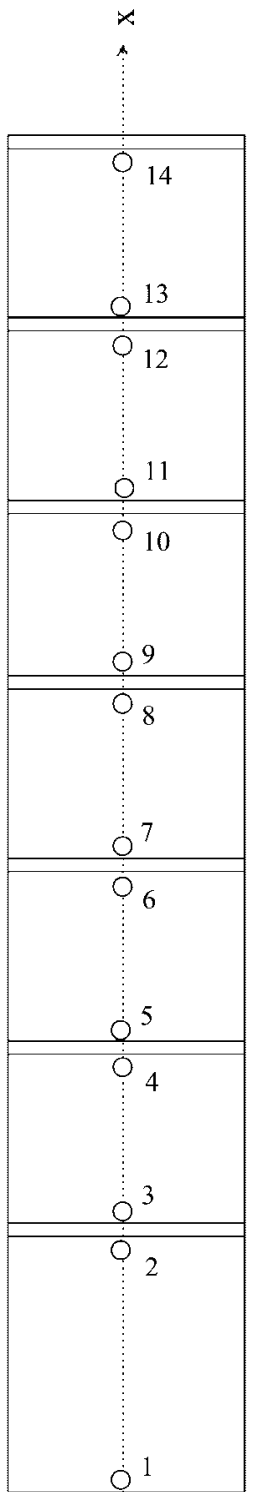

Figure 5. One-dimensional model showing 14 points at which the 'top of story' and 'bottom of story' displacements and rotations are presented in the following figures.

The building in the numerical model is discretized as follows. The floor layers are discretized with three spatial intervals, while the number of the equal spatial intervals of the story (soft) layers is $n_{k}=3 \cdot h_{k} / h_{14}$, where the subscript stands for the layer number. Thus, we obtain an equidistant grid in the inter-story layers $(k=1,3,5, \ldots, 13)$ with spatial interval

$$
\Delta x_{k}=\frac{h_{k}}{n_{k}}=\frac{h_{14}}{3}
$$




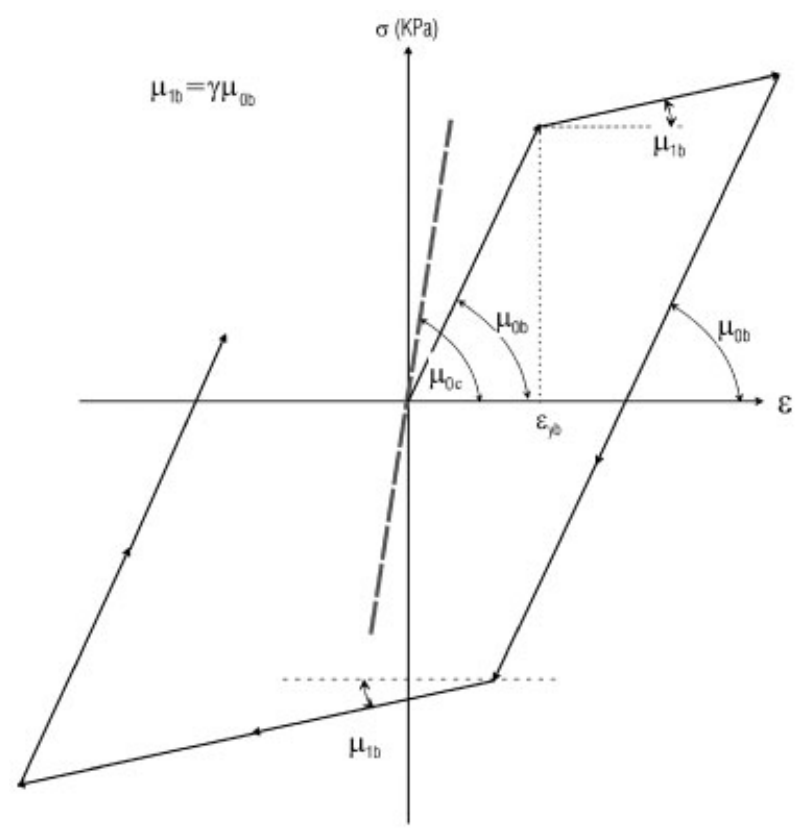

Figure 6. Bi-linear constitutive law used in the finite-difference calculations of the response of VN7SH.

while at the floor levels $(k=2,4,6, \ldots, 14)$ the spatial interval is

$$
\Delta x_{k}=\frac{h_{k}}{3}
$$

and at the contact points $i$ the spatial interval is

$$
\Delta x_{i}=\frac{\Delta x_{i+1}+\Delta x_{i-1}}{2}
$$

where $i$ stands for the ordered number of the contact point. The numerical tests have shown that this discretization leads to stable results. In this way, the model is represented by a grid having 295 points and 294 intervals.

Above the top point $(N=295)$, an additional dummy point $N^{\prime}$ is introduced at distance $\Delta x_{14}$ from the point $N$. For a stress-free point $N$, for all time, the velocities and the stress at point $N^{\prime}$ are updated as

$$
\begin{gathered}
v_{N^{\prime}}=v_{N-1} \\
\sigma_{N^{\prime}}=-\sigma_{N-1}
\end{gathered}
$$

Equations (1a), (1b) can be written in vector form as

$$
\frac{\partial \mathbf{U}}{\partial t}=\frac{\partial \mathbf{F}}{\partial x}
$$


where

$$
\mathbf{U}=\left\{\begin{array}{l}
v \\
\epsilon
\end{array}\right\} \text { and } \mathbf{F}=\left\{\begin{array}{c}
\frac{\sigma}{\rho} \\
v
\end{array}\right\}
$$

The vector $\mathbf{U}$ at point $i$ in time $(j+1) \Delta t$ expanded in a Taylor series is

$$
\mathbf{U}_{i, j+1}=\mathbf{U}_{i, j}+\Delta t\left(\frac{\partial \mathbf{U}}{\partial t}\right)_{i, j}+\frac{\Delta t^{2}}{2}\left(\frac{\partial^{2} \mathbf{U}}{\partial t^{2}}\right)_{i, j}+O\left(\Delta t^{3}\right)
$$

and from Equation (5)

$$
\begin{gathered}
\mathbf{U}_{i, j+1}=\mathbf{U}_{i, j}+\Delta t\left(\frac{\partial \mathbf{F}}{\partial x}\right)_{i, j}+\frac{\Delta t^{2}}{2} \frac{\partial}{\partial t}\left(\frac{\partial \mathbf{F}}{\partial x}\right)_{i, j}+O\left(\Delta t^{3}\right) \\
\mathbf{U}_{i, j+1}=\mathbf{U}_{i, j}+\Delta t\left(\frac{\partial \mathbf{F}}{\partial x}\right)_{i, j}+\frac{\Delta t^{2}}{2} \frac{\partial}{\partial x}\left(\mathbf{A}(\mathbf{U}) \frac{\partial \mathbf{F}}{\partial x}\right)_{i, j}+O\left(\Delta t^{3}\right)
\end{gathered}
$$

where $\mathbf{A}(\mathbf{U})$ is the Jacobian matrix

$$
\mathbf{A}(\mathbf{U})=\frac{\partial \mathbf{F}}{\partial \mathbf{U}}=\left[\begin{array}{cc}
\frac{\partial \sigma}{\rho \partial v} & \frac{\partial \sigma}{\rho \partial \epsilon} \\
\frac{\partial v}{\partial v} & \frac{\partial v}{\partial \epsilon}
\end{array}\right]=\left[\begin{array}{cc}
0 & \frac{1}{\rho} \frac{\mathrm{d} \sigma}{\mathrm{d} \epsilon} \\
1 & 0
\end{array}\right]
$$

\section{RESULTS}

The inter-story drifts are average rotations of the deformed shape of the simplified $k$-degrees-offreedom building model, where $k$ is the number of building slabs +1 (and +1 is associated with the prescribed motion at the soil-building interface). The deformed shape of this model is piecewise linear.

Between adjacent slabs, $i$ and $i+1(i+1 \leqslant k)$, the average rotation (drift) is

$$
\operatorname{drift}(i)=\left(\frac{u_{i+1}(t)-u_{i}(t)}{h_{i}}\right) \quad(i=1,2, \ldots, k-1)
$$

where $u$ represents the slab displacement and $h$ is the height of the soft layer.

As we consider continuous model of the building, the deformed shape of the soft layer representing columns is a continuous curve of higher order, and its rotations (strains), $\varepsilon$, at each point between two adjacent slabs are different. Because the drift represents average rotation of the soft layers, by Lipshitz condition there is a point (not necessarily in the middle of the soft layer) where the point rotation of the continuous model is equal to the average rotation (drift). The conclusion is that the difference between the drift and the point rotations in the continuous model is largest at the end points of the column.

To study the difference between the drifts and point rotations (strains), we consider the 14 points just below and above the slabs (at distance $\Delta x=6.8 \mathrm{~cm}$ below and above the slabs) (see marked points 1-14 in Figure 5). In each time step, using (9), we compute the seven inter-story drifts. At the same time, having computed strains from the FD scheme at the 14 points at the end of each soft layer (columns), we compute seven pairs of ratio

$$
r(2 i-1)=\frac{\epsilon(2 i-1)}{\operatorname{drift}(i)}
$$




$$
r(2 i)=\frac{\epsilon(2 i)}{\operatorname{drift}(i)}
$$

In Equations (10), $i$ represents the layer (soft story) number $(i=1,2, \ldots, 7)$.

To avoid division by zero, we introduce a small number $\delta=0.001$. For small values of the drift, if the absolute value of the drift is smaller than $\delta$, we take the limit

$$
\lim _{\operatorname{drift}(i) \rightarrow 0} r(2 i-1)=\lim _{\operatorname{drift}(i) \rightarrow 0} r(2 i)=1
$$

In Figure 7, the ratios at the bottoms and tops of the soft layers (columns) are presented versus time.

During large nonlinear response, these ratios are different from 1 (point rotations are bigger or smaller than the average floor drift).

\section{ANALYSIS}

The ratios of the rotations shown in Figure 7 are plotted with higher resolution in Figures $8(\mathrm{a}-\mathrm{d})$, for the four time windows $3.00-5.35,5.35-7.75,7.75-10.20$, and $10.20-12.00 \mathrm{~s}$. In these figures, we show how the 'characteristic departures from 1' (CDF1) of the rotational ratio propagate up and down the building. It can be seen that in the beginning, while the ground

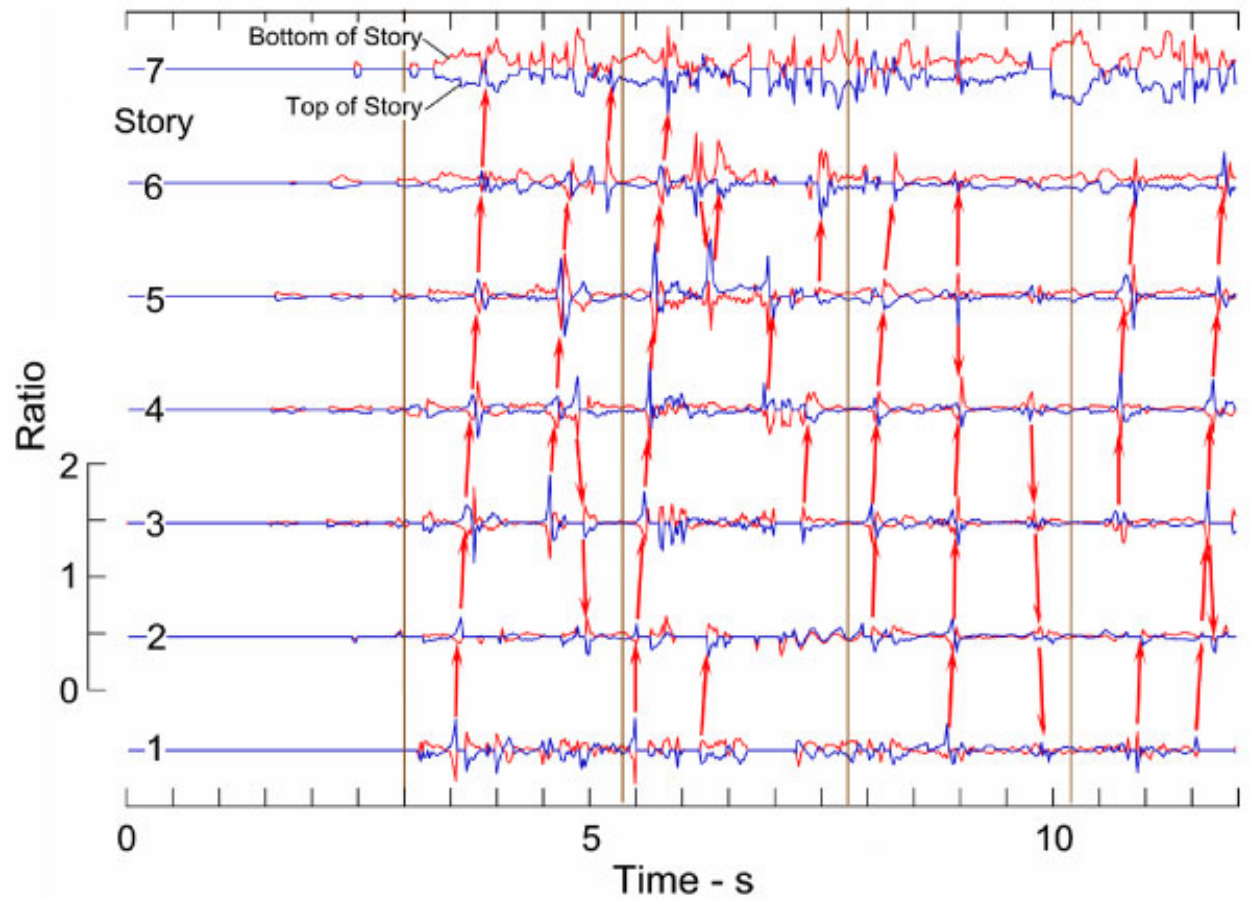

Figure 7. Ratios of the point rotations at the top and bottom of each floor to the average rotation (drift) of the corresponding floor, computed at the 14 points shown in Figure 5. Propagation of characteristic 'waveforms', showing initiation of nonlinear strains, is shown by arrows. 
motion is still relatively small and nonlinear response is just beginning to occur, the velocity of CDF1 is still reasonably close to the linear velocities in the model (as given in Table I). As the motions become larger, velocities of CDF1 drop, typically to values between 40 and $50 \mathrm{~m} / \mathrm{s}$, but in some instances to values as low as $19 \mathrm{~m} / \mathrm{s}$. While the largest CDF1 propagate up, there are several obvious cases of propagation down.

\subsection{Energy distribution in the model}

Because the model we study represents a conservative system, the kinetic and elastic part of potential energies, the energy radiated out from the building into the soil, and the energy spent for development of the permanent strains in the building must add up to the incident-wave energy [19]. The input energy, $E_{\text {in }}$, can be computed from the input displacement record (Figure 4). First, by differentiation of the displacement record with respect to time, the input particle velocity is obtained. The input energy, assuming that the cross section of the model is $A=1 \mathrm{~m}^{2}$, is then computed assuming vertically propagating $1 \mathrm{D}$ plane waves:

$$
E_{\text {in }}=\rho_{\mathrm{s}} \cdot \beta_{\mathrm{s}} \int_{0}^{T} v^{2} \mathrm{~d} t \cong \rho_{\mathrm{s}} \cdot \beta_{\mathrm{s}} \cdot \sum_{k=1}^{M} v_{k}^{2} \cdot \Delta t
$$

where $\rho_{\mathrm{s}}$ and $\beta_{\mathrm{s}}$ are the density and the shear-wave velocity of the soil, respectively, $v=\partial u_{0} / \partial t$ is the input particle velocity, $T$ is the time at the end of the record, $k$ is the order number of a time step, $M=T / \Delta t$ is the discrete time at the end of the record, and $v_{k}=\left(u_{0, k}-u_{0, k-1}\right) / \Delta t$ for $k>1$, and $v_{1}=u_{0,1} / \Delta t$ for $k=1$, are the discrete particle velocities.

The output energy, $E_{\text {out }}$, is computed from the velocity of the wave going downward, $v_{\text {out }}$, $[19,40]$. The cumulative output energy is then

$$
E_{\text {out }}=\rho_{\mathrm{s}} \cdot \beta_{\mathrm{s}} \int_{0}^{T} v^{2} \mathrm{~d} t \cong \rho_{\mathrm{s}} \cdot \beta_{\mathrm{s}} \cdot \sum_{k=1}^{M}\left(v_{\text {out }}^{k}\right)^{2} \cdot \Delta t
$$

The hysteretic energy, $E_{\text {hys }}$, is the energy spent on the development of permanent strains in the building. The hysteretic loop (Figure 6) represents the relation $\sigma(\epsilon)$ at a point during one cycle of the response $T_{0, i}<t<T_{0, i+1}$, where $T_{0,1}=4 \cdot \sum_{j=1}^{14} h_{j} / \beta_{j} \approx 0.8 \mathrm{~s}$ can be used to approximate the apparent period of the building. Depending upon the input ground motion and the time during strong motion, the loop in Figure 6 can be narrower or wider. By adding the areas of those loops and assuming no strength reduction from repetitive loads, we can compute the energy spent for the development of permanent strains at a specific point. Next, we generalize this for a layer (continuous equivalent representation of the columns and walls at a given floor), and for the whole building. The hysteretic energy for a specific layer is obtained as the sum of the loops at the points belonging to that layer, while the hysteretic energy for the whole building is obtained as the sum of the energies in all layers. The hysteretic energy in the building (the points $i=1,2$ are soil points and $i=3$ is the point at the soil-building contact) in discrete time space is

$$
E_{\mathrm{hys}}=\sum_{i=3}^{N} \Delta x_{i} \cdot \sum_{k=1}^{M} \sigma_{\mathrm{av}}^{k} \cdot \Delta \epsilon^{k}
$$

where the indices $i$ and $k$ stand for spatial and temporal discrete points of the model. $N$ is the point representing the top of the building, and $M$ is the point representing the end of the record. $\sigma_{\mathrm{av}}^{k}=\left(\sigma^{k}+\sigma^{k-1} / 2\right)$ is the average stress at a point $i$ in the time step $k$, and $\Delta \epsilon^{k}$ is the strain increment at point $i$ in the $k$ th time step. The points in the slabs do not contribute to the 

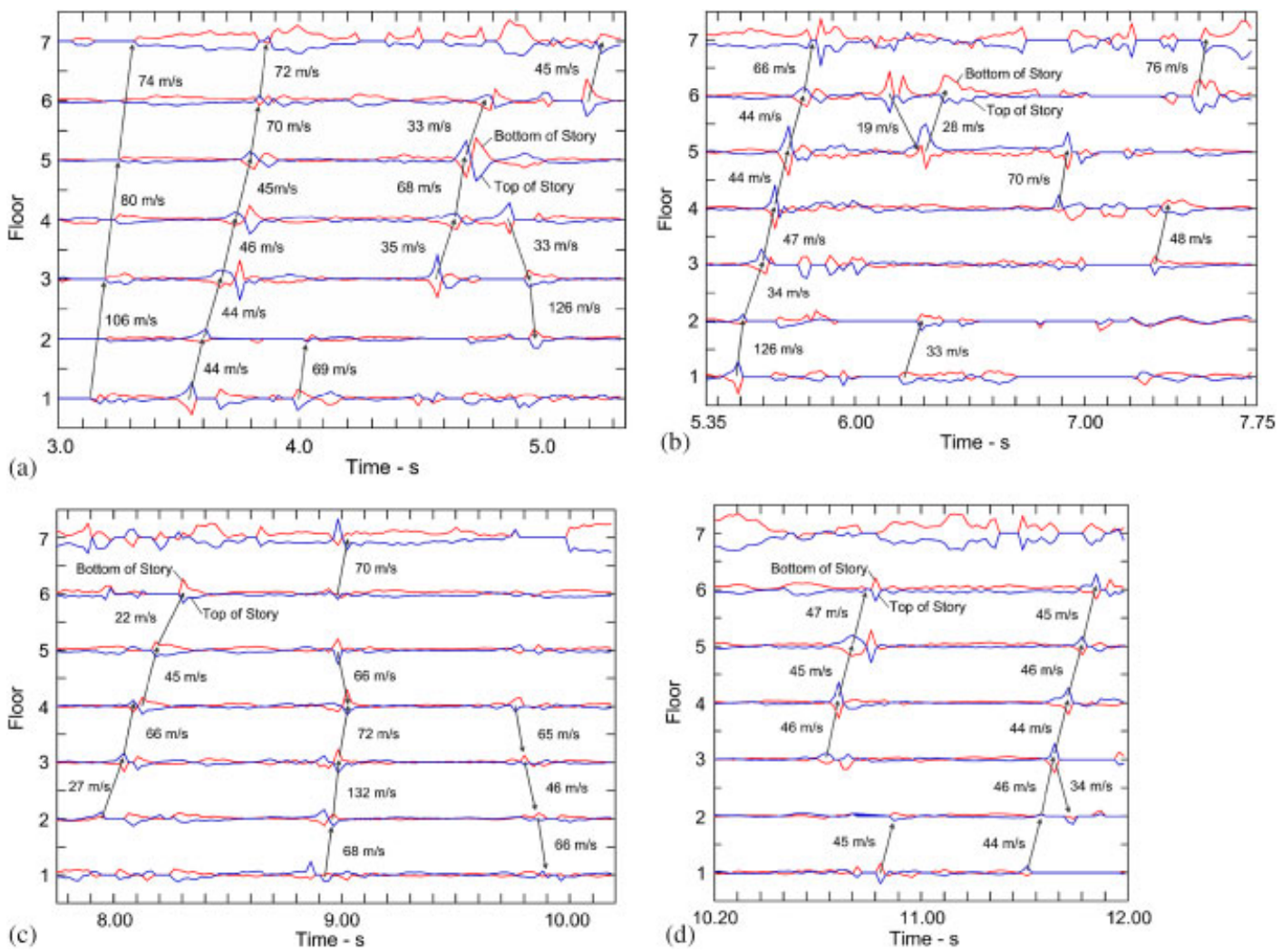

Figure 8. (a) Same as Figure 7, except that more detail is shown for the time window 3-5.35 s; (b) same as Figure 7, except that more detail is shown for the time window 5.35-7.75 s; (c) same as Figure 7, except that more detail is shown for the time window 7.75-10.20 s; and (d) same as Figure 7, except that more detail is shown for the time window $10.20-12.00 \mathrm{~s}$.

hysteretic energy because those are assumed to remain linear and only transmit the wave energy to the layers above and below. After about $t=12 \mathrm{~s}$ of ground motion during the Northridge earthquake, there is negligible growth of all energies [19], and therefore in the following we illustrate the results only for the first $12 \mathrm{~s}$ of strong motion.

Subtracting from the input energy (Equation (12)) the output (radiated) energy (Equation (13)), we obtain the instantaneous energy in the building. The difference

$$
E_{\mathrm{el}}^{\mathrm{b}}=E_{\mathrm{b}}-E_{\mathrm{hys}}
$$

then represents the instantaneous elastic (linear) energy in the building. Until the end of the record, one part of the elastic energy is radiated, contributing to the output energy $E_{\text {out }}$, and one part is spent for development of permanent strains, contributing to the hysteretic energy $E_{\text {hys }}$.

A part of energy in the building is reversible. During loading, a fraction of the elastic energy transforms into hysteretic energy, and vice versa, during unloading, a part of the hysteretic energy is converted back into elastic energy. 


\subsection{Energy and power capacities and demands in the building}

To understand the behavior of CDF1 in the VN7SH building during the Northridge earthquake, we also consider the energy and power capacities of different floors. To determine the energy capacity for one period, $E_{T_{0}}$, we consider the hysteretic loop at a point in the building during which the point reaches the strain $\epsilon_{u}$. Following Gičev and Trifunac [19], we compute the energy capacity of the point $i$ per one cycle as

$$
E_{T_{0}}^{i}=4 \cdot \mu_{0 i} \cdot \epsilon_{\mathrm{yb}}^{2} \cdot(1-\gamma) \cdot(d-1)
$$

While energy capacity per one cycle gives information about the capacity of the floor (soft layer) for oscillatory loading, the energy capacity of the floor $i$ during one quarter period, $E_{\mathrm{q}}^{i}$, gives information about its resistance during a single monotonic loading. Gičev and Trifunac [19] showed that

$$
E_{\mathrm{q}}^{i}=\frac{\mu_{0 i} \cdot \epsilon_{\mathrm{yb}}^{2}}{2} \cdot\left[1+2(d-1)+\gamma \cdot(d-1)^{2}\right]
$$

The power is the derivative of energy with respect to time. We compute the power capacity per full cycle by dividing Equation (16) by the period of the building, $T_{0}$, and the power capacity for quarter cycle by dividing Equation (17) by $T_{0} / 4$ :

$$
\begin{gathered}
P_{T_{0}}^{i}=4 \cdot \mu_{0 i} \cdot \epsilon_{\mathrm{yb}}^{2} \cdot(1-\gamma) \cdot(d-1) / T_{0} \\
P_{q}^{i}=2 \mu_{0 i} \cdot \epsilon_{\mathrm{yb}}^{2} \cdot\left[1+2(d-1)+\gamma \cdot(d-1)^{2}\right] / T_{0}
\end{gathered}
$$

From Equations (18) and (19), it can be seen that the power capacity for one full period is linearly dependent upon the ductility, $d$, while the power capacity for one quarter period (loading only) depends upon the square of the ductility.

Figures 9(a), (b) show normalized power demands for two time windows, from 3 to $5.35 \mathrm{~s}$ and from 8 to $10.20 \mathrm{~s}$, in terms of the relative power. In these figures, the relative power is plotted in terms of the ratio of $P_{\text {hys }}$, which is the time rate of change of $E_{\text {hys }}$ (see Equation (14)) normalized (divided) by $P_{c, \text { quart }}=P_{q}^{i} \cdot h_{i}$ (see Equation (19)), calculated for $d=10$. It can be seen that this power ratio approaches 2 at the fourth and seventh floors, while at the fifth and sixth floors it is near 3 at around $4 \mathrm{~s}$. At the third, fourth, fifth, and sixth floors, this ratio exceeds 1 at around $5.2 \mathrm{~s}$. The same ratio exceeds 5, for example, at the third, fourth, fifth, and sixth floors between 8.5 and $8.8 \mathrm{~s}$, and again at the fifth floor at around $9.2 \mathrm{~s}$. The largest peak of the ratio $P_{\text {hys }} / P_{c, \text { quart }}(d=10)$ occurred on the fourth floor, with an amplitude larger than 8 at about $8.6 \mathrm{~s}$. These results are in excellent agreement with the location of the observed post-earthquake damage on the same floor (Figures 2 and 3) and with the analyses of the peak strains and peak drifts in the response of the 1D model of VN7SH to the Northridge earthquake [39].

Further perusal of the largest peaks of the power ratios, $P_{\text {hys }} / P_{c, \text { quart }}(d=10)$ (Figures 9 (a), (b)), will show that they occur in sequence, at progressively higher floors, and at times following the entrance of the strong pulses from the ground motion into the building. The local peak ratios occur in Figure 9(a) at around $4 \mathrm{~s}$ (at floors 3-6) and $5.2 \mathrm{~s}$ (at floors 1-6), and in Figure 9(b) at around 8.4 s (at floors 1-6) and 9.2 s (at floors 4-6). These power pulses caused damage along their path whenever and wherever the power ratio exceeded the value of about 2. From the time delays between these consecutive pulses in Figures 9(a), (b), we can estimate the average wave speeds associated with the propagation of their energies. Around 4 and $5 \mathrm{~s}$ (in Figure 9(a) this speed is about $45 \mathrm{~m} / \mathrm{s}$ ). At around $8.5 \mathrm{~s}$, and $10.2 \mathrm{~s}$ (in Figure 9(b)), the speed is lower, about 

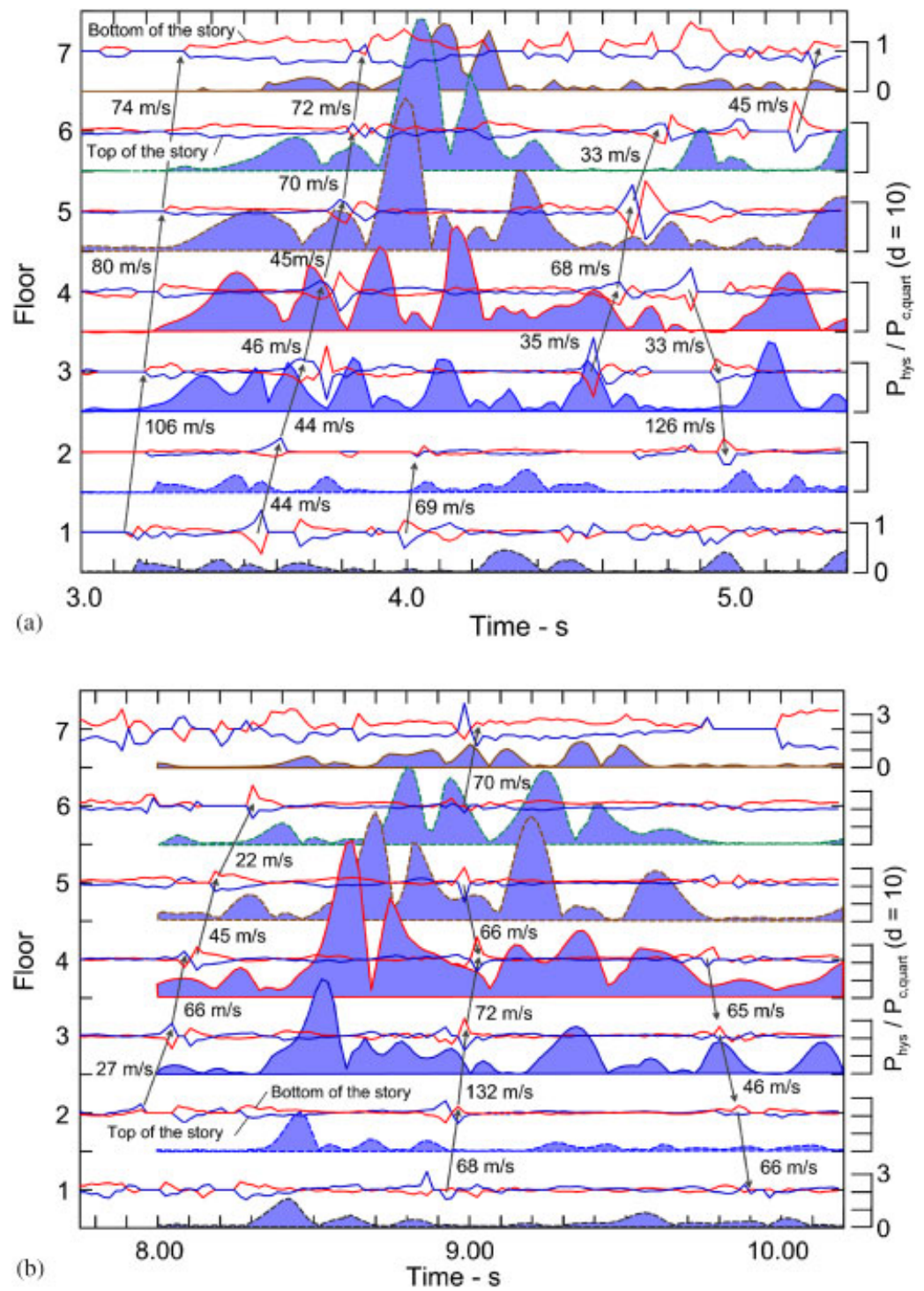

Figure 9. (a) Ratios of point and average floor rotations at the top and bottom of each floor compared with the relative power $P_{\text {hys }} / P_{c, \text { quart }}(d=10)$, showing that both propagate up and down the building with comparable speeds. The time interval $3.00-5.35 \mathrm{~s}$ is shown and (b) same as Figure 9(a), but for time interval $7.75-10.20 \mathrm{~s}$.

$35 \mathrm{~m} / \mathrm{s}$. Comparing these speeds with the initial (linear) velocities in our model (Table I), which range from $73 \mathrm{~m} / \mathrm{s}$ (seventh story) to $91 \mathrm{~m} / \mathrm{s}$ (third story) to $140 \mathrm{~m} / \mathrm{s}$ (first story), it can be concluded that the lower speeds resulted from nonlinear deformations in the model and the interference of nonlinear waves. Their values and their times of occurrence are consistent with the results of other direct [21,22] and indirect analyses of the nonlinear waves in the VN7SH [39] 
and show trends similar to what has been seen in other buildings damaged by strong-motion waves [24,25]. The typical velocities with which the normalized power propagated up the building are similar to the velocities of CDF1, which is also reproduced in Figures 9(a), (b). It is seen that CDF1 occur during relatively 'quiet' periods of power propagation and seem to be associated with local adjustments in displacement to bring to equilibrium the deformations and rotations imparted by the powerful pulses of power waves.

\subsection{Displacements}

Figure 10 shows the displacements in the model (Figure 5) subjected to ground motion recorded during the 1994 Northridge earthquake (Figure 4). For each of the seven stories (soft layers), the motions at the top and bottom of that story are shown. The light vertical lines at 3.00, 5.35, 7.75, and $10.20 \mathrm{~s}$ are shown for easier comparison with Figures 8 and 9.

It is seen that the largest departures from the ratio of one (CDF1) are consistently initiated when the displacements at the top and bottom of a given story intersect (are equal). It can also be seen that the tops of all stories are consistently moving with larger positive amplitudes when a wave carrying large power propagates through that story, moving upward (e.g. just after 4, 8, and $10 \mathrm{~s}$ in Figure 10). As the displacements at the top and the bottom of a soft layer become equal, the available potential and hysteretic energies are redistributed by slow rotational (strain) waves locally through several floors, and sometimes through the full height of the building.

\subsection{Point rotations}

Figure 11 shows the point rotations (at the top and bottom of each story) corresponding to the displacements shown in Figure 10. It can be seen that the point rotations are largest during two

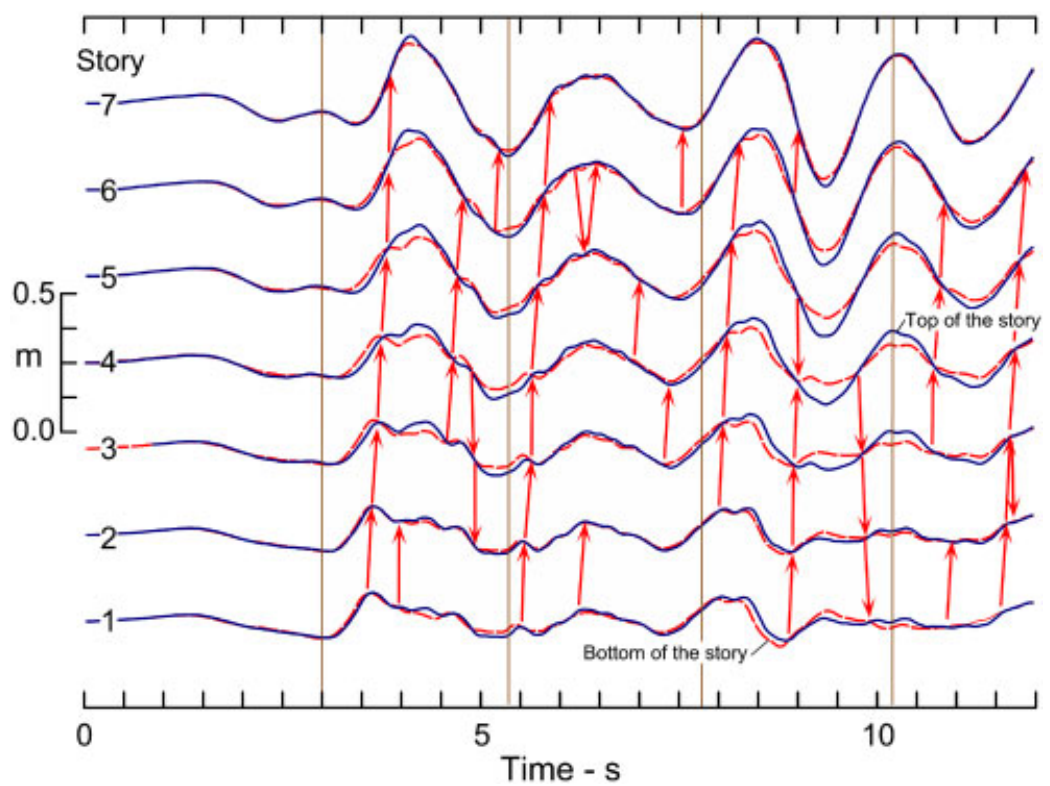

Figure 10. Displacements at the 14 points shown in Figure 5, and propagation of the point rotations up and down the building where the corresponding average drifts are equal to zero. 


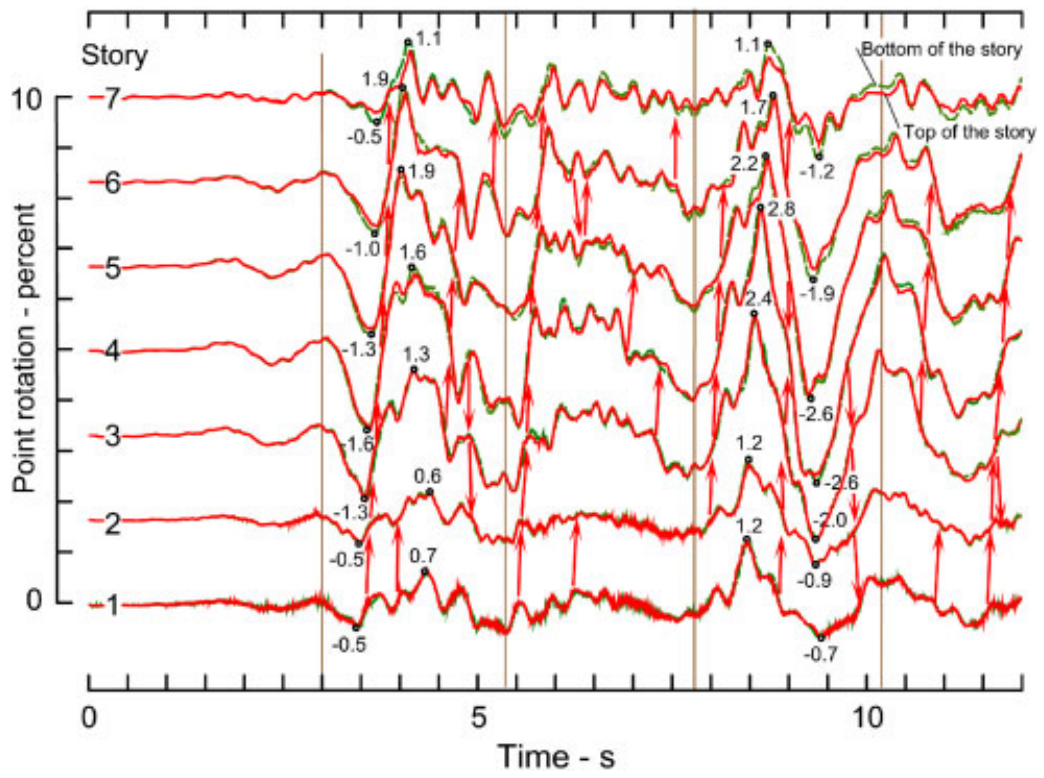

Figure 11. Point rotations at the tops and bottoms of stories versus time. Peak rotations in percentages $(1 \%=0.01 \mathrm{rad})$ during strongest motions are shown.

episodes - from 3 to $5 \mathrm{~s}$ and from 8 to $10 \mathrm{~s}$. During the first strong power wave, which starts to propagate up the building just after $3 \mathrm{~s}$ (see Figure 9(a), the point rotations approach 1.5-2\% $(0.02 \mathrm{rad})$ at the fourth and fifth floors. After $8 \mathrm{~s}$, a power wave about three times larger propagates up the building and results in the point rotations, which are in the range between 2.5 and $3 \%$, twice at the fourth floor and once at the fifth floor. The damage to the building, as observed after the earthquake (Figures 2 and 3), is consistent with these large rotations, which imply initiation of damage at the fourth floor at around $4 \mathrm{~s}$ and then the full development of failure during the time interval from 8 to $10 \mathrm{~s}$.

In Figure 12, we show the displacements from Figure 10 together with the average floor rotations (drifts). It can be seen that the onset of large rotations and the rapid swings of the rotations from negative to positive values, and vice versa, begin just after the appearance of CDF1. This suggests that monitoring of CDF1 can provide the real-time precursors for the occurrence of large rotations associated with nonlinear response. Figures 13(a), (b) show more detailed comparisons of the normalized power (for $d=10$ ) and the point rotations for the two time windows $3-5.35$ and $7.75-10.25 \mathrm{~s}$. Again, the CDF1 occurs during changes in sign of the rotations and just before or after the propagation of significant power waves up and down the building.

\subsection{Curvatures}

In the engineering theory of bending, member curvatures can be related to the design capacity of structural members and serve as a useful indicator of the degree of the bending at a point, 


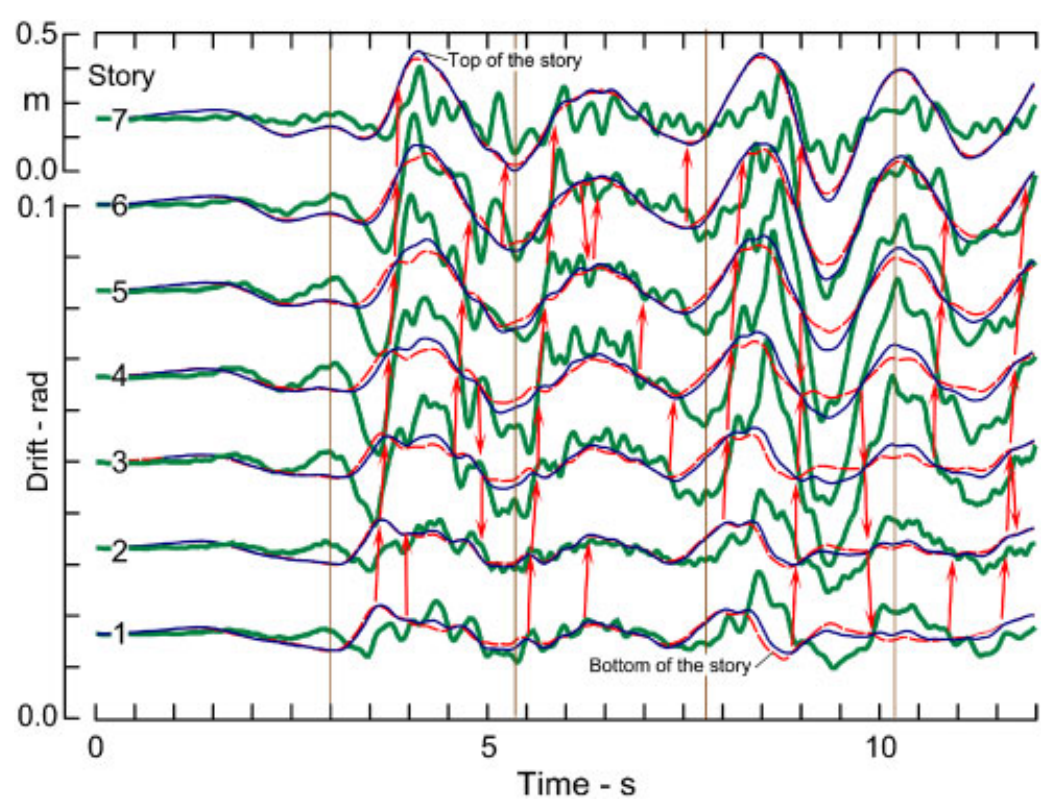

Figure 12. Comparison of displacements at the top and bottom points of each floor with corresponding average drifts (wide continuous lines).

imposed by the dynamic loads. In the shear-beam model adopted for this analyses the local curvatures do not represent the member curvatures, but can serve to indicate large relative rotations associated with nonlinear response and accompanying passage of waves with large local power in the structures and in the soil [42]. We compute the point curvature in the shearbeam model of the VN7SH building as

$$
\kappa=\frac{\epsilon_{x}}{\left(1+\epsilon^{2}\right)^{3 / 2}}
$$

which is equivalent to

$$
\kappa=\frac{u_{x x}}{\left(1+u_{x}^{2}\right)^{3 / 2}}
$$

where $u$ is particle displacement. The difference between the curvature in (20) and

$$
\kappa \approx \epsilon_{x}
$$

is negligible, because for all examples considered in this paper $\epsilon^{2} \ll 1$.

Further consideration of Equations (20) and (21), in combination with Equation (1a), shows that the velocity of shear waves in the $1 \mathrm{D}$ shear beam, when $\epsilon^{2} \ll 1$, is equal to $\left[u_{t t} / \kappa\right]^{1 / 2}$. Thus, for the buildings equipped with dense arrays consisting of instruments capable of recording translational accelerations $u_{t t}$ and point rotations, real-time computation of $\left[u_{t t} / \kappa\right]^{1 / 2}$ will provide data on real-time changes of shear-wave velocity, and its anomalous behavior (drop) in the zones of strain localization associated with large nonlinear deformations. This suggests that real-time monitoring of $\left[u_{t t} / \kappa\right]^{1 / 2}$ can be used in the real-time evaluation of structural health. 

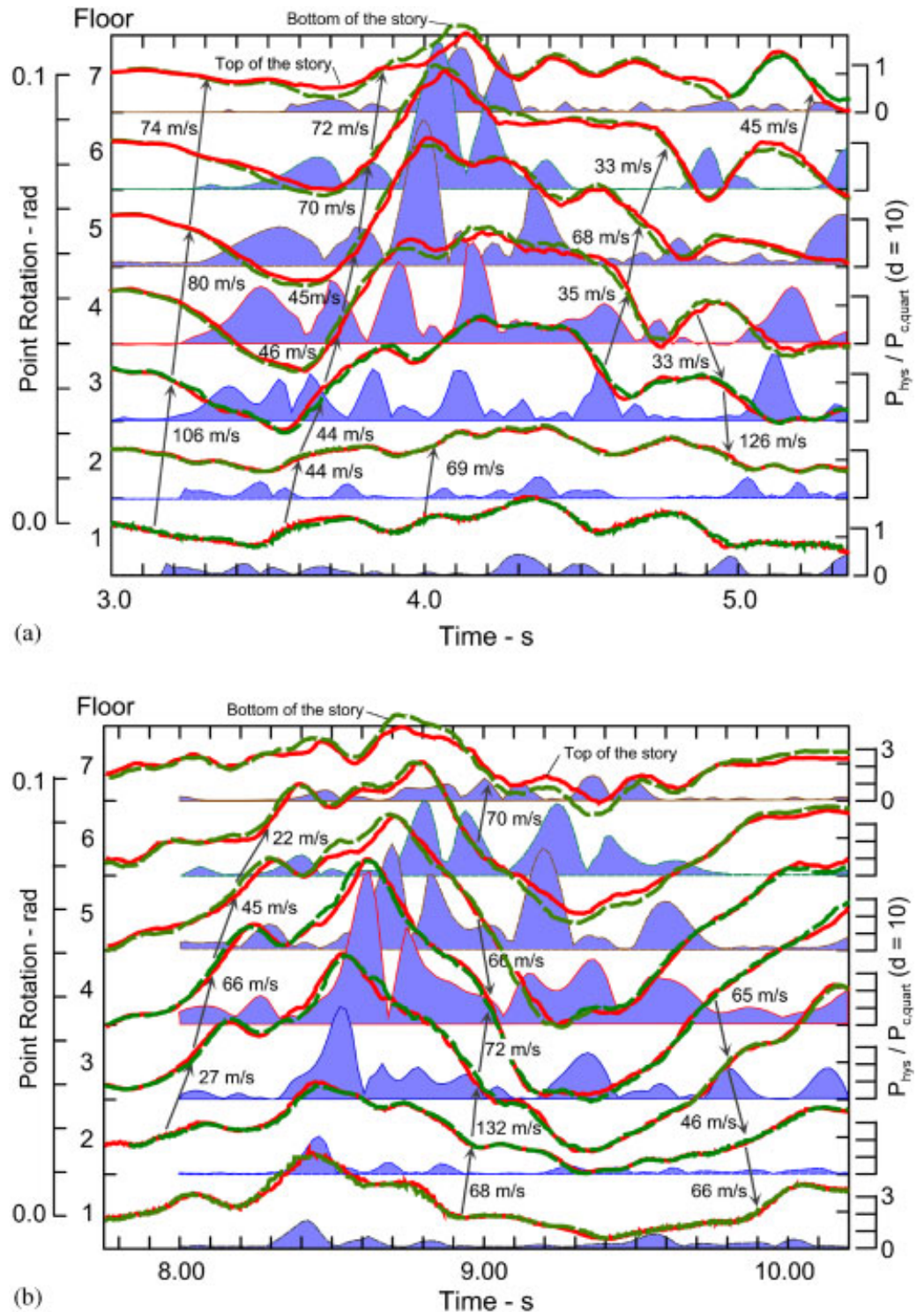

Figure 13. (a) Comparison of point rotations with relative wave power, for time window $3-5.35 \mathrm{~s}$ and (b) same as Figure 13(a), but for time window 7.75-10.20s.

Figure 14 shows curvatures $\kappa(1 / \mathrm{m})$ at the top and at the bottom of the soft layers in all seven stories of our model of the VN7SH (Figure 5). For comparison with all previous figures, with few exceptions, most of the arrows identified in Figures 7 and 8 are shown as well. Figures 15(a) and (b) show further detail for the two time windows between 3.00 and $5.35 \mathrm{~s}$, and between 7.75 and $10.20 \mathrm{~s}$. It is seen that during propagation of the damaging power waves, up and down the 


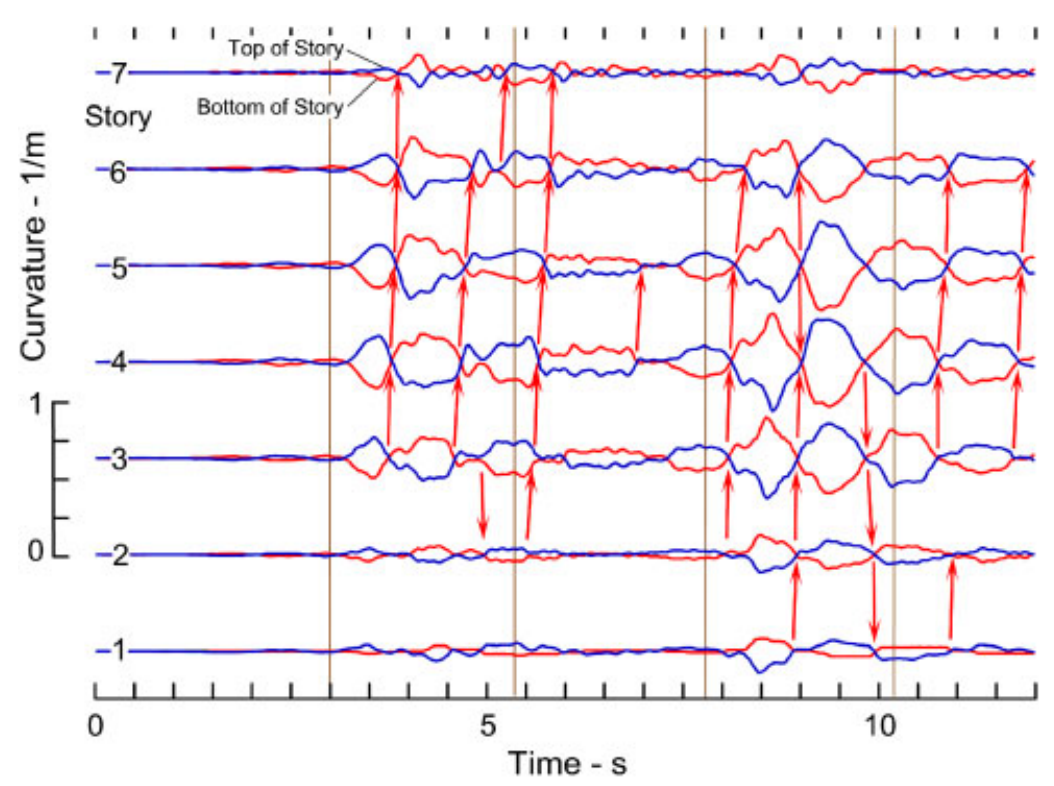

Figure 14. Point curvatures at tops and bottoms of stories versus time.

building model, curvatures are large. The largest curvatures in this example, $0.311 / \mathrm{m}$ (at the bottom) and $-0.321 / \mathrm{m}$ (at the top), occurred at the fourth floor, just after $t=8.6 \mathrm{~s}$, at the same time when peak strain occurs.

\section{SUMMARY AND CONCLUSIONS}

The power (energy and its duration) of the strong pulses in the near-field ground motion will determine whether the wave entering the structure will continue to propagate through the structure as a linear wave or begin to create nonlinear zones. For high-frequency pulses, the nonlinear zone, with permanent strains, can be created before the wave motion reaches the top of the structure-i.e. before the interference of waves (which leads to the formation of mode shapes) has even started to occur. The overall duration of strong motion [43] will determine the number of times the structure may be able to complete full cycles of response and the associated number of 'minor' excursions into the nonlinear response range when the response is weakly nonlinear [44]. The presence of powerful pulses of strong motion will determine the extent to which the one-directional quarter period responses may lead to excessive ductility demand, leading in turn to dynamic instability and failure precipitated by the gravity loads [45]. As large waves propagate through the structure and deform its members beyond their linear range of response, the creation of nonlinear response zones and their localization (plastic hinges) will give rise to the zones of large local rotations (strains). These large rotations will also behave as waves, which will redistribute the available potential and hysteretic energies remaining after the passage of powerful pulses up and down the building. Recording these rotations and the CDF1 can provide an invaluable tool for local damage detection. 

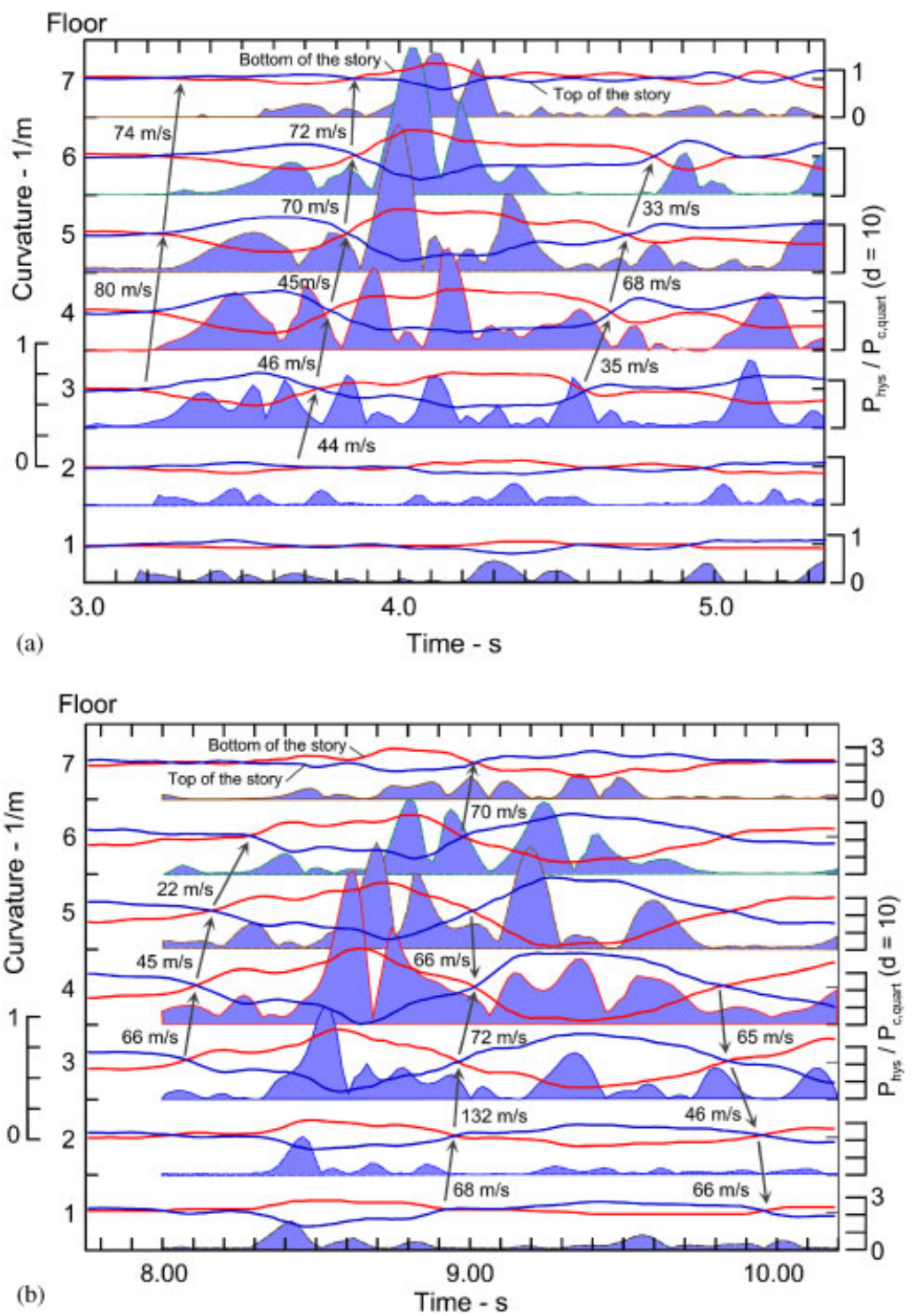

Figure 15. (a) Same as Figure 14, but for time window 3.00-5.35 s, showing that both curvature and power, $P_{\text {hys }} / P_{c, \text { quart }}(d=10)$, propagate up and down the building with comparable speeds and $(\mathrm{b})$ same as Figure 15(a), but for time window from 7.75 to $10.20 \mathrm{~s}$.

In this paper, we modeled the building by a simple 1D, shear-beam model having bi-linear material properties. Consequently, our model can give only a rough, first-order approximation of actual response. While it is known that overall building deformation can be modeled successfully with a shear-beam model, modeling of individual beams and columns will require more detailed models, which will locally include the Euler-Bernoulli bending theory. It is 


\section{GIČEV AND M. D. TRIFUNAC}

expected that the plastic hinges accompanying bending, which will be associated with strain localization, will lead to larger point rotations than those observed in this study. By placing small-aperture arrays of rotational transducers on beams and columns, it will be possible to achieve the next level in the resolution of point deformations because from closely spaced rotational sensors it will be possible to also record the point curvature.

\section{REFERENCES}

1. Doebling SW, Farrar CR, Prime MB, Shevitz DW. Damage identification and health monitoring of structural and mechanical systems from changes in their vibration characteristics: a literature review. Report LA-13070-MS, Los Alamos National Laboratory, Los Alamos, NM, 1988.

2. Chang PC, Flatau A, Liu SC. Review paper: health monitoring of civil infrastructure. Structural Health Monitoring 2003; 2(3):257-267.

3. Browning JA, Li RY, Lynn A, Moehle JP. Performance assessment for a reinforced concrete frame building. Earthquake Spectra 2000; 16(3):541-555.

4. De la Llera JC, Chopra AK, Almazan JL. Three-dimensional inelastic response of an RC building during the Northridge earthquake. Journal of Structural Engineering - ASCE 2001; 127(5):482-489.

5. Islam MS. Analysis of the Response of an Instrumented 7-story Nonductile Concrete Frame Building Damaged During the Northridge Earthquake, Professional Paper 96-9. Los Angeles Tall Buildings Structural Design Council: Los Angeles, CA, 1996.

6. Li RY, Jirsa JD. Nonlinear analysis of an instrumented structure damaged in the 1994 Northridge earthquake. Earthquake Spectra 1998; 14(2):265-283.

7. Kanai K. Some problems of seismic vibration of structures. Proceedings of the Third World Conference Earthquake Engineering, vol. II, New Zealand, 1965; 260-275.

8. Todorovska MI, Lee VW. Seismic waves in buildings with shear walls or central core. Journal of Engineering Mechanics-ASCE 1989; 115(12):2669-2686.

9. Todorovska MI, Al Rjoub Y. Plain strain soil-structure interaction model for a building supported by a circular foundation embedded in a poroelastic half-space. Soil Dynamics and Earthquake Engineering 2006; 26(6-7):694-707.

10. Todorovska MI, Al Rjoub Y. Effects of rainfall on soil-structure system frequency: examples based on poroelasticity and a comparison with full-scale measurements. Soil Dynamics and Earthquake Engineering 2006; 26(6-7):708-717.

11. Todorovska MI, Trifunac MD. Antiplane earthquake waves in long structures. Journal of Engineering MechanicsASCE 1989; 115(12):2687-2708.

12. Todorovska MI, Trifunac MD. A note on the propagation of earthquake waves in buildings with soft first floor. Journal of Engineering Mechanics-ASCE 1990; 116(4):892-900.

13. Todorovska MI, Trifunac MD. A note on excitation of long structures by ground waves. Journal of Engineering Mechanics-ASCE 1990; 116(4):952-964.

14. Safak E. Wave propagation formulation of seismic response of multi-story buildings. Journal of Structural Engineering-ASCE 1999; 125(4):426-437.

15. Ivanović S, Trifunac MD, Todorovska MI. On identification of damage in structures via wave travel time. Proceedings of the NATO Workshop on Strong Motion Instrumentation for Civil Engineering Structures, Istanbul, Turkey. Kluwer Academic Publishers: Dordrecht, Turkey, 1999; 447-468.

16. Trifunac MD, Ivanovic SS, Todorovska MI. Wave propagation in a seven-story reinforced concrete building, III: damage detection via changes in wave numbers. Soil Dynamics and Earthquake Engineering 2001; 23(1):65-75.

17. Ma J, Pines DJ. Damage detection in a building structure model under seismic excitation using dereverberated wave mechanics. Engineering Structures 2003; 25:385-396.

18. Gičev V, Trifunac MD. Permanent deformations and strains in a shear building excited by a strong motion pulse. Soil Dynamics and Earthquake Engineering 2007; 27(8):774-792.

19. Gičev V, Trifunac MD. Energy and power of nonlinear waves in a seven story reinforced concrete building. Indian Society of Earthquake Technology Journal 2007; 44(1):305-323.

20. Snieder R, Safak E. Extracting the building response using interferometry: theory and applications to the Millikan Library in Pasadena, California. Bulletin of the Seismological Society of America 2006; 96(2):586-598.

21. Todorovska MI, Trifunac MD. Impulse response analysis of the Van Nuys 7-story hotel during 11 earthquakes (1971-1994): one-dimensional wave propagation and inferences on global and local reduction of stiffness due to earthquake damage. Department of Civil Engineering Report CE 06-01, University of Southern California, Los Angeles, CA, 2006.

22. Todorovska MI, Trifunac MD. Impulse response analysis of the Van Nuys 7-story hotel during 11 earthquakes and earthquake damage detection. Structural Control and Health Monitoring 2008; 15(1):90-116. 


\section{ROTATIONS IN A SHEAR-BEAM MODEL OF A SEVEN-STORY BUILDING}

23. Todorovska MI, Trifunac MD. Earthquake damage detection in the Imperial County Services Building I: the data and time-frequency analysis. Soil Dynamics and Earthquake Engineering 2007; 26(6):564-576.

24. Todorovska MI, Trifunac MD. Earthquake damage detection in the Imperial County Services Building II: analysis of novelties via wavelets. Soil Dynamics and Earthquake Engineering, 2008 (submitted for publication).

25. Todorovska MI, Trifunac MD. Earthquake damage detection in the Imperial County Services Building III: analysis of wave travel times via impulse response functions. Soil Dynamics and Earthquake Engineering, 2008 (in press).

26. Trifunac MD. A note on rotational components of earthquake motions for incident body waves. Soil Dynamics and Earthquake Engineering 1982; 1(1):11-19.

27. Moslem K, Trifunac MD. Effects of soil-structure interaction on the response of buildings during strong earthquake ground motion. Department of Civil Engineering Report No. CE 86-04, University of Southern California, Los Angeles, CA, 1986.

28. Trifunac MD, Todorovska MI. Recording and interpreting earthquake response of full-scale structures. In Proceedings of the NATO Workshop on Strong Motion Instrumentation for Civil Engineering Structures, Instanbul, Turkey, Erdik M, Celebi M, Mihailov V, Apaydin N (eds). Kluwer Academic Publishers: Turkey, 2001; 131-155.

29. Trifunac MD, Ivanovic SS. Analysis of drifts in a seven-story reinforced concrete structure. Department of Civil Engineering Report No. CE 03-01. University of Southern California, Los Angeles, CA, 2003. Can be downloaded from http://www.usc.edu/dept/civil_eng/Earthquake_eng/.

30. Ivanović SS, Trifunac MD, Novikova EI, Gladkov ĀA, Todorovska MI. Instrumented 7-story reinforced concrete building in Van Nuys, California: ambient vibration surveys following the damage from the 1994 Northridge earthquake. Department of Civil Engineering Report No. CE 99-03. University of Southern California, Los Angeles, CA, 1999. Can be downloaded from http://www.usc.edu/dept/civil eng/Earthquake eng/.

31. Trifunac MD, Hao TY. 7-Story reinforced concrete building in Van Nuys, California: photographs of the damage from the 1994 Northridge earthquake. Department of Civil Engineering Report No. CE 01-05. University of Southern California, Los Angeles, CA, 2001. Can be downloaded from http://www.usc.edu/dept/civil_eng/Earthquake_eng/.

32. Trifunac MD, Ivanović SS, Todorovska MI, Novikova EI, Gladkov AA. Experimental evidence for flexibility of a building foundation supported by concrete friction piles. Soil Dynamics and Earthquake Engineering 1999; 18(3):169-187.

33. Trifunac MD, Ivanović SS, Todorovska MI. Seven story reinforced concrete building in Van Nuys, California: strong motion data recorded between 7 February 1971 and 9 December 1994, and description of damage following Northridge, 17 January 1994 Earthquake. Department of Civil Engineering Report No. 99-02. University of Southern California, Los Angeles, CA, 1999.

34. Blume JA, and Assoc. Holiday Inn. San Fernando, California Earthquake of February 9, 1971, Vol. I, Part A, Chapter 29. U.S. Department of Commerce, National Oceanic and Atmospheric Administration, Washington, DC, 1973.

35. Mulhern MR, Maley RP. Building period measurements before, during and after the San Fernando, California, Earthquake of February 9, 1971, Vol. 1, Part B. U.S. Department of Commerce, National Oceanic and Atmospheric Administration, Washington, DC, 1973; 725-733.

36. Trifunac MD, Todorovska MI. Damage distribution during the 1994 Northridge, California, earthquake in relation to generalized categories of surface geology. Soil Dynamics and Earthquake Engineering 1998; 17(4): $238-252$.

37. Trifunac MD, Ivanović SS, Todorovska MI. Apparent periods of a building, part I: Fourier analysis. Journal of Structural Engineering-ASCE 2001; 127(5):517-526.

38. Trifunac MD, Ivanovic SS, Todorovska MI. Apparent periods of a building, part II: time-frequency analysis. Journal of Structural Engineering - ASCE 2001; 127(5):527-537.

39. Gičev V, Trifunac MD. Non-linear earthquake waves in seven-story reinforced concrete building. Department of Civil Engineering Report CE 06-03. University of Southern California, Los Angeles, CA, 2006. Can be downloaded from http://www.usc.edu/dept/civil_eng/Earthquake_eng/.

40. Gičev V, Trifunac MD. Rotations in the transient response of nonlinear shear beam. Department of Civil Engineering Report CE 06-02. University of Southern California, Los Angeles, CA, 2006. Can be downloaded from http:// www.usc.edu/dept/civil_eng/Earthquake_eng/.

41. Lax PD, Wendroff B. Difference schemes for hyperbolic equations with high order of accuracy. Communications on Pure and Applied Mathematics 1964; XVII: 381-398.

42. Trifunac MD. Curvograms of strong ground motion. Journal of Structural Engineering-ASCE 1990; 116(6):1426-1432.

43. Trifunac MD, Novikova EI. State of the art review on strong motion duration. Proceedings of the 10th European Conference on Earthquake Engineering, Vienna, Austria, vol. I, 1994; 131-140.

44. Gupta ID, Trifunac MD. Investigation of nonstationarity in stochastic seismic response of structures. Department of Civil Engineering Report CE 96-01. University of Southern California, Los Angeles, CA, 1996. Can be downloaded from http://www.usc.edu/dept/civil_eng/Earthquake_eng/.

45. Husid R. Gravity effects on the earthquake response of yielding structures. Ph.D. Thesis, California Institute of Technology, Pasadena, CA, 1967. 